\title{
Effect of Glenohumeral Joint Rotation on Serratus Anterior, Pectoralis Major and Upper Trapezius EMG Activity during Push-up Plus Exercise
}

\author{
Young-Hun Shim¹, Ki-Seok Nam², Ji-Won Park ${ }^{3}$ \\ 'Department of Physical Therapy, Rehabilitation medicine, Samsung Medical Center, Seoul; ${ }^{2}$ Department of Physical Therapy, Yeungnam College of \\ Science and Technology Daegu; ${ }^{3}$ Department of Physical Therapy, College of Medical Science, Catholic University of Daegu, Gyeongsan, Korea
}

Purpose: The aim of this study is to determine the effect of glenohumeral $(\mathrm{GH})$ rotation position in modified knee push-up plus exercise (MKPUP) by examining the surface electromyography (EMG) amplitude in serratus anterior (SA), pectoralis major (PM), and upper trapezius (UTz) and the activity ratio of each muscle.

Methods: A total of 22 healthy subjects volunteered for the study. Each subject performed the MKPUP at $0^{\circ}, 45^{\circ}$, and $90^{\circ}$ of $\mathrm{GH}$ joint internal rotation. EMG of the SA and PM, UTz was compared between $\mathrm{GH}$ rotation positions and each muscle activity ratio. EMG was used to measure the muscle activity in terms of ratios to maximal voluntary isometric contraction (MVIC).

Results: The difference in EMG activity during the exercise in three $\mathrm{GH}$ joint internal rotation positions was observed with the SA and the PM. The greater the GH joint internal rotation angle was, the lower the activity of the PM. In contrast, the SA showed higher activity. However, the activity of UT was similar under all conditions. The ratio of the SA and the PM was considerably greater at $90^{\circ} \mathrm{GH}$ joint internal rotation than at $0^{\circ}$ and $45^{\circ}$.

Conclusion: When excessive activation of the PM or imbalanced activation between the PM and the SA occurs, the MKPUP exercise is most effective at $90^{\circ}$ of $\mathrm{GH}$ joint internal rotation. Use of this position would be a beneficial strategy for selective strengthening of the SA and minimizing PM activation.

Keywords: Serratus anterior, pectoralis major, upper trapezius, Push-up plus, Glenohumaral rotation position

\section{서 론}

어깨뼈(scapula) 주위근육들은 팔을 들어올리는 동작을 하는 동안 어 깨뼈를 안정화시켜서 어깨복합체(shoulder girdle)의 정상적인 움직임 을 만들어낸다. 그중에 앞톱니근(serratus anterior), 위등세모근(upper trapezius), 아래등세모근(lower trapezius)들의 힘의 조합이 어깨뼈의 안정화에 영향을 준다. 특히, 앞톱니근은 다른 어깨뼈 주위근육들보 다 어깨뼈의 위쪽돌림(upward rotation)과 뒤쪽경사(posterior tipping) 를 만들어내는 데 주된 역할을 한다. ${ }^{3}$ 그래서 앞톱니근은 정상적인 어깨뼈의 움직임 패턴과 조절에 있어서 가장 중요한 근육으로 다뤄 졌다. 팔을 들어올릴 때의 어깨뼈의 움직임을 3-D로 보면 앞톱니근 이 가슴우리(thorax)에서 위팔뼈(humerus)의 움직임을 최대로 만들 어주기 위해 정상적인 오목위팔관절(glenohumeral joint) 움직임을 유

Received Mar 22, 2016 Revised Apr 27, 2016

Accepted May 2, 2016

Corresponding author Ji-Won Park

E-mail mylovept@hanmail.net
지해 주고 봉우리밑 공간(subacromial space)을 확보하는 데 있어서도 임상적으로 중요한 역할을 한다는 것을 알 수 있다.1,4 이러한 연관성 에 비추어 봤을 때, 앞톱니근의 약화는 위/아래등세모근의 활동을 과하게 이끌어 내고 그로 인해 어깨복합체의 안정성이 깨지고 비정 상적인 움직임을 나타나게 된다.5.6 실제 오목위팔관절의 불안정성(instability), ${ }^{5}$ 어깨충돌증후군(impingement syndrome), ${ }^{1}$ 어깨 통증을 호 소하는 수영선수 ${ }^{6}$ 에게서 앞톱니근의 근활성도가 떨어져 있는 근거 들이 있다. 결국 앞톱니근은 어깨기능장애를 치료하고 예방하는 데 있어서 가장 집중해야하는 근육인 것이다.

어깨복합체와 관련된 여러 운동들을 연구한 선행논문에서 앞톱 니근 근활성도의 특성을 확인한 결과, 이 근육의 근활성을 이끌어 낼 수 있는 가장 효과적인 운동으로 push-up plus (PUP) 운동을 보고하 였다.-11 예를 들어 Moseley 등1ㅡㄴ 앞톱니근의 근활성도를 이끌어내 
는 기본적인 어깨 운동으로 Standard Push-up plus (SPUP) 운동을 보고 하였고 Decker 등 은 SPUP 운동 중에서도 특히 Plus 단계에서 앞톱니 근의 근활성도가 더 높았다고 보고하였다. 변형된 PUP 운동들은 임 상에서 많이 사용하고 있으며 여기에는 knee push-up plus, elbow pushup plus, and wall push-up plus 등이 있고 각각의 변형된 PUP 운동들은 서로 비등하게 앞톱니근의 근활성도를 이끌어낸다고 보고하였다.

여러 가지 어깨 운동들에서 위등세모근과 앞톱니근의 근활성도와 공력근(synersist)으로서의 비율(ratio)에 대해 연구되었다.,212,13 비정상 적인 어깨 움직임을 가지고 있는 대상자를 기준으로 위등세모근과 앞톱니근의 근활성 비율과 함께 앞톱니근과 큰가슴근(pectoralis major)의 유의한 차이도 보고되었다., ${ }^{1,7,8,14,15}$ 게다가, 돌출 어깨뼈(scapular winging)가 있는 대상자에게 PUP 운동 중, 특히 plus 단계를 수행하는 동안 앞톱니근에 비해서 큰가슴근의 강력한 활동이 보여진다고 보 고하였고, ${ }^{15}$ 그러한 운동 단계에서 큰가슴근은 앞톱니근을 대신하여 사용된다는 것을 의미한다. ${ }^{78,14}$ 그래서, 우리는 PUP 운동 중 큰가슴 금의 근활성도를 떨어뜨리고 앞톱니근의 근활성도가 더 크게 나타 나게 해야 한다. 큰가슴근은 오목위팔관절의 안쪽돌림근이다. 네발 기기 자세에서 오목위팔관절의 돌림 위치(rotation position)는 위팔의 돌림 위치에 달려있다. 그렇다면 PUP 운동 중에 위팔의 돌림 위치는 큰가슴근의 근활성도에 영향을 줄 수 있다. ${ }^{16,17}$ 본 연구는 오목위팔관 절에서 위팔의 돌림 위치에 따른 앞톱니근, 큰가슴근과 위등세모근

Table 1. General characteristics

\begin{tabular}{|c|c|c|c|c|}
\hline Characteristics & & & Mean & SD \\
\hline Gender & Male & 17 & & \\
\hline Dominant side & Right & 17 & & \\
\hline Age (year) & & & 29.97 & 4.52 \\
\hline Height (cm) & & & 175.28 & 4.57 \\
\hline Weight (kg) & & & 69.75 & 7.96 \\
\hline Arm length $(\mathrm{cm})$ & & & 58.12 & 3.02 \\
\hline Upper arm length (cm) & & & 35.59 & 2.43 \\
\hline Between table depth (cm) & & & 22.53 & 1.59 \\
\hline
\end{tabular}

Between table depth = arm length - upper arm length. SD: standard deviation.
의 근활성도를 연구하여 각각의 근활성도의 차이와 서로의 비율이 위팔의 돌림 위치에 얼마나 영향을 받는지 확인하고자 한다. 본 연구 는 PUP 운동에 대해 보다 학술적으로 이해하는 기초자료를 제공할 것이며 어깨 손상 환자들의 재활을 위한 프로그램 개발 시 유익한 자 료로 활용될 수 있을 것으로 기대된다.

\section{연구방법}

\section{1. 연구대상}

본 연구는 경상북도 C대학교에 재학 중인 건강한 남학생 17 명을 대 상으로 실시하였다. 피험자들 모두 근육뼈대계, 신경계, 순환계에 이 상이 없었으며 어깨와 관련된 질환이나 수술의 병력이 없고, 일주일 에 5 시간 이상 정기적으로 근력 운동을 하는 대상자는 제외하였다. 모든 대상자는 실험에 참가하기 전 실험의 내용과 절차에 대해 충분 한 설명을 듣고 실험동의서에 서명하였으며, 자발적으로 실험에 참여 하였다 (Table 1).

\section{2. 실험방법}

1) 측정 도구

위팔의 돌림 위치를 다르게 하기 위해 변형된 PUP 운동 중에 modified knee push-up plus (MKPUP) (Figure 1A, B)운동을 통해 실험을 실

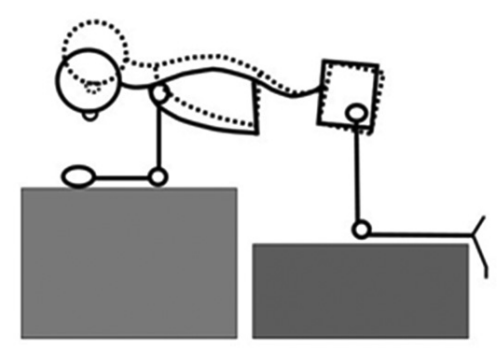

Modified knee push-up plus exercise

A GH rotation position B

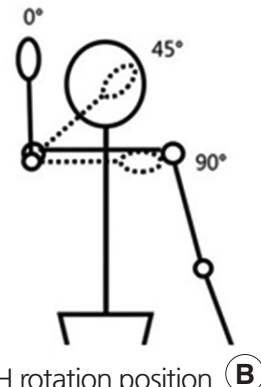

Figure 1. Modified knee push-up plus with glenohumeral $(\mathrm{GH})$ joint rotation.

Table 2. The mean EMG data of the SA, PM, and UTz muscles, and the SA/PM, UTz/PM, and SA/UTz ration during modified push-up plus in three $\mathrm{GH}$ rotation positions

$(\mathrm{N}=17)$

\begin{tabular}{|c|c|c|c|c|c|}
\hline \multirow{2}{*}{ Muscle } & \multicolumn{3}{|c|}{ GH rotation position (Mean $\pm S D$ ) } & \multirow{2}{*}{$\mathrm{F}$} & \multirow{2}{*}{$p$} \\
\hline & $0^{\circ}$ & $45^{\circ}$ & $90^{\circ}$ & & \\
\hline PM (\%MVIC) & $35.82 \pm 15.41$ & $39.26 \pm 17.08$ & $34.08 \pm 12.22$ & 5.143 & $0.02^{\star}$ \\
\hline SA (\%MVIC) & $71.91 \pm 20.59$ & $77.13 \pm 22.38$ & $80.33 \pm 22.56$ & 3.786 & $0.047^{\star}$ \\
\hline UTz (\%MVIC) & $18.18 \pm 5.77$ & $17.63 \pm 6.36$ & $19.60 \pm 6.30$ & 3.272 & 0.066 \\
\hline SA/PM ratio & $2.16 \pm 0.17$ & $2.12 \pm 0.16$ & $2.53 \pm 0.20$ & 6.061 & $0.012^{*}$ \\
\hline UTz/PM ratio & $0.54 \pm 0.16$ & $0.48 \pm 0.15$ & $0.16 \pm 0.20$ & 9.07 & $0.003^{*}$ \\
\hline SA/UTz ratio & $4.21 \pm 1.48$ & $4.69 \pm 1.67$ & $4.53 \pm 2.15$ & 7.001 & $0.007^{\star}$ \\
\hline
\end{tabular}

SA: serratus anterior, PM: pectoralis major, UTz: upper trapezius, GH: glenohumeral ${ }^{*} p<0.05$. 
시하였다. MKPUP 운동 시 위팔 돌림 위치에 따른 SA, PM, and UTz의 근활성도 차이와 서로의 비율을 측정하기 위해 8 채널 무선전극 근전 도(LAXTHA, LXM5308)를 사용하였다. 근전도 신호의 표본추출율 은 $1,024 \mathrm{~Hz}$ (1,000 samples/second)로 설정하였으며 증폭된 파형은 10$500 \mathrm{~Hz}$ 의 대역통과필터(band pass filter)로 필터링하였고 $60 \mathrm{~Hz}, 120$ $\mathrm{Hz}$ 노치필터(notch filter)를 사용하였다.

\section{2) 실험 절차 및 방법}

(1) 근전도 신호 수집 및 분석

표면 근전도 신호에 대한 피부 표면의 저항을 제거하기 위해서 면도 칼로 제모 후, 소독용 알코올로 피부 저항을 제거하고, 전극을 피부 에 부착하였다. ${ }^{18}$ 피부의 움직임으로 인한 전극 부착지점의 이동을 최소화하기 위해 옆으로 누워 오목위팔관절 $90^{\circ}$ 굽힘 자세에서 전극 을 부착하였다. 대상자의 우세쪽 앞톱니근, 위등세모근, 큰가슴근의 근육이 가장 발달된 근복(muscle belly)에, 중심간 거리가 $20 \mathrm{~mm}$ 인 양 극성 근전도 표면전극 $(\mathrm{Ag} / \mathrm{AgCl}$ surface bipolar electrodes, Tyco Healthcare Korea, Seoul, Korea)을 수평방향으로 부착하였다. ${ }^{19}$ 큰가슴근 (sternal fiber)은 앞쪽 겨드랑이 주름(anterior axillary fold)에서 바깥으 로 $2 \mathrm{~cm}$ 지점에, 위등세모근은 제7번 목뼈 가시돌기와 어깨봉우리 바 깥쪽의 중간 지점에, 앞톱니근은 어깨뼈 아래각 높이에서 넓은등근 안쪽으로 겨드랑이에 부착하였다. 접지전극(ground electrode)은 측 정하는 반대 측의 빗장뼈에 부착하였다. 본 연구에서는 근육의 활동 전위를 정량화하기 위해 각 근육에 대한 맨손 근력 검사를 통해 최대 등척성 수축(maximal voluntary isometric contraction, MVIC) 동안 근 활성도를 측정하고, ${ }^{20,21} \mathrm{MVIC}$ 에 대한 5 초 동안의 각 근육별 근전도 신호는 root mean square (RMS) 방법으로 처리한 후 처음과 마지막 1 초를 제외한 중간 3 초 동안의 평균 근전도 신호량을 사용하였고, MKPUP 수행 동안 각 근육별 근전도 신호량은 RMS 방법으로 처리 한 후 그 중앙값을 분석에 활용하여 $\% \mathrm{MVIC}$ 를 산출하였다. ${ }^{22} \mathrm{MVIC}$ 에 대한 근전도 신호량 수집은 각각 2 회 실시한 근전도 신호의 평균 값을 사용하였고 측정 간 근피로 방지를 위해 2 분간 휴식시간을 주 었다. ${ }^{19}$

\section{(2) 실험 과정}

모든 연구 대상자는 오목위팔관절의 돌림위치의 변화를 주기 위해 아래팔은 뒤침-엎침(supination-pronation) 없이 중립위치에 두고 손을 편안하게 편 상태로 앞쪽 $\left(0^{\circ}\right)$, 손바닥 겹침 $\left(45^{\circ}\right)$, 아래팔 겹침 $\left(90^{\circ}\right)$ 의 3 가지 조건에서 MKPUP 운동을 실시하였다(Figure 1B). 3 가지 조건에 서의 MKPUP 자세와 움직임 수행을 표준화(standardization)하고 불 필요한 움직임을 통제하기 위하여 시작자세, 운동 수행 과정을 조작 적으로 정의하였다.
대상자는 다음과 같은 시작자세를 취했다. 팔꿈치를 $90^{\circ}$ 굽힘 상태 에서 팔꿈치를 어깨넓이로 벌려 테이블을 짚는다. 일반적인 네발기기 (quadruped position) 형태를 유지하기 위해 두 테이블의 높이차이는 전체 팔길이(acromion-radius styloid process)에서 위팔길이(acromionolecranon process)를 뺀 값만큼 차이를 두고 양 팔꿈치와 양 무릎으 로 체중을 지지하게 하였다. 턱을 당겨 목뼈를 안정화시킨 상태에서 연구자의 “시작”이라는 구호와 함께 연구대상자가 MKPUP 운동을 실시하도록 하였다. 어깨뼈의 내밀기(protraction)동작을 할 때 등과 허리 및 목의 중립자세가 잘 유지되도록 하며 미리 설정해 놓은 시간 타이머와 함께 7초간 유지하게 하였다. 등의 굽힘만 일어나는 어깨뼈 의 내밀기 동작이 나타나지 않아야 하며 앞 또는 뒤쪽으로의 락킹 (foreward or backward rocking)이 일어나지 않아야 한다(Figure 1A). 모 든 연구대상자에게 구두지시와 시범을 통한 10 분간의 익숙화(familiarization)를 통하여 MKPUP 동작을 숙지하도록 하였다. 표준화된 시 작자세, 운동수행 동작이 수행되지 않을 경우 자료 수집을 하지 않고 3 가지 조건을 각각 3 회씩 반복 측정하였다. 총 9회의 측정 순서는 무 작위로 정하였고 근피로를 예방하기 위해 각 수행 사이에 2 분간의 휴 식을 취했다.

\section{3) 자료 분석}

오목위팔관절의 돌림위치의 변화에 따른 큰가슴근, 위등세모근, 그 리고 앞톱니근의 근활성도와 서로의 비율을 비교하기 위해 반복측 정 분산분석(a one-way repeated measures ANOVA)을 사용하였다. 통 계학적 유의 수준을 검정하기 위하여 $\alpha=0.05$ 하였으며 자료의 통계 분석을 위하여 SPSS version 20.0 프로그램을 사용하였다.

\section{결 과}

\section{1. 오목위팔관절 돌림위치에 따른 큰가슴근의 근활성도 비교}

큰가슴근의 근활성도를 분석한 결과, 오목위팔관절의 $45^{\circ}$ 돌림위치 에서의 근활성도가 $0^{\circ}, 90^{\circ}$ 돌림위치에서의 근활성도보다 높게 나타 났다 $\left(0^{\circ}: 35.82 \pm 15.41 \% \mathrm{MVIC} ; 45^{\circ}: 39.26 \pm 17.08 \% \mathrm{MVIC} ; 90^{\circ}: 34.08 \pm\right.$ 12.22) (Table 2, Figure 2). 오목위팔관절 $0^{\circ}$ 와 $45^{\circ}$ 돌림위치에서의 큰가 슴근 근활성도는 유의한 차이가 있었으나 $(\mathrm{p}<0.05) 45^{\circ}$ 와 $90^{\circ}, 0^{\circ}$ 와 $90^{\circ}$ 돌림위치에서는 유의한 차이가 보이지 않았다 $(\mathrm{p}<0.05)$.

\section{2. 오목위팔관절 돌림위치에 따른 앞톱니근의 근활성도 비교}

앞톱니근의 근활성도를 분석한 결과, 오목위팔관절의 $0^{\circ}, 45^{\circ}, 90^{\circ}$ 돌 림위치에서의 근활성도가 순차적으로 증가되었다 $\left(0^{\circ}: 71.91 \pm 20.59\right.$ \%MVIC; $45^{\circ}: 77.13 \pm 22.38 \%$ MVIC; $90^{\circ}: 80.33 \pm 22.56$ ) (Table 2, Figure 2). 오목위팔관절 $0^{\circ}$ 와 $45^{\circ}, 0^{\circ}$ 와 $90^{\circ}$ 돌림위치에서의 앞톱니근 근활성도 


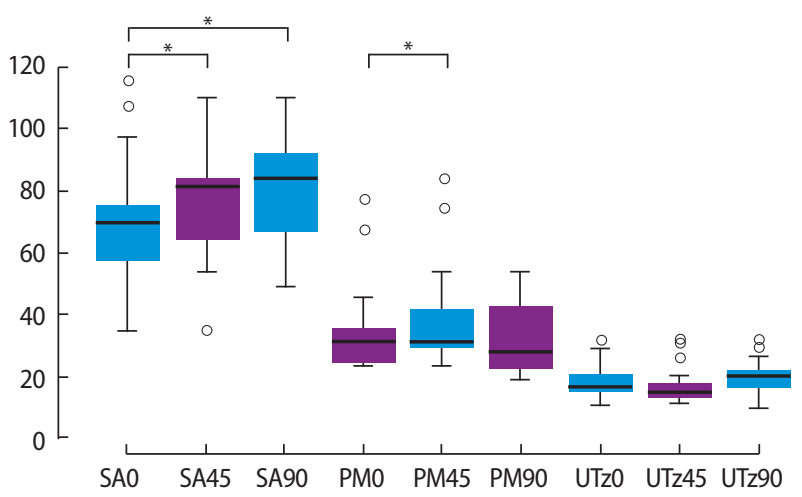

Figure 2. Comparision of SA, PM and UTz EMG activity during three $\mathrm{GH}$ joint rotation position. SA: serratus anterior, PM: pectoralis major, UTz: upper trapezius, 045 90: GH joint rotation degree, GH: glenohumeral. ${ }^{*} p<0.05$, significant simple effect.

는 유의한 차이가 있었으나 $(\mathrm{p}<0.05), 45^{\circ}$ 와 $90^{\circ}$ 돌림위치에서는 유의 한 차이가 보이지 않았다 $(\mathrm{p}>0.05)$

\section{3. 오목위팔관절 돌림위치에 따른 위등세모근의 근활성도 비교}

위등세모근의 근활성도를 분석한 결과, 오목위팔관절의 $45^{\circ}$ 돌림위 치에서의 근활성도가 $0^{\circ}, 90^{\circ}$ 돌림위치에서의 근활성도보다 높게 나 타났다 $\left(0^{\circ}: 18.18 \pm 5.77 \% \mathrm{MVIC} ; 45^{\circ}: 17.63 \pm 6.36 \% \mathrm{MVIC} ; 90^{\circ}: 19.60 \pm\right.$ 6.30) (Table 2, Figure 2). 오목위팔관절의 돌림위치에서의 위등세모근 근활성도는 각각 유의한 차이가 보이지 않았다 $(\mathrm{p}>0.05)$.

\section{4. 오목위팔관절 돌림위치에 따른 각 근육들의 근활성도 비율}

오목위팔관절 돌림위치에 따른 앞톱니근/큰가슴근, 위등세모근/큰 가슴근, 앞톱니근/위등세모근들의 각 근활성도 비율을 비교하였다 (Table 2, Figure 3). 앞톱니근/큰가슴근 비율은 $90^{\circ}$ 돌림위치가 $0^{\circ}$ 와 $45^{\circ}$ 돌림위치보다 유의하게 높게 나타났다 $\left(0^{\circ}: 2.16 \pm 0.17 ; 45^{\circ}: 2.12 \pm 0.16\right.$; $90^{\circ}: 2.53 \pm 0.20$ ). 앞톱니근/큰가슴근 비율은 $0^{\circ}$ 와 $45^{\circ}, 0^{\circ}$ 와 $90^{\circ}$ 돌림위 치에서는 유의한 차이가 있었으나 $(\mathrm{p}<0.05) 0^{\circ}$ 와 $45^{\circ}$ 돌림위치에서는 유의한 차이가 보이지 않았다 $(\mathrm{p}>0.05)$.

위등세모근/큰가슴근 비율은 $90^{\circ}$ 돌림위치가 $0^{\circ}$ 와 $45^{\circ}$ 돌림위치보 다 유의하게 높게 나타났다 $\left(0^{\circ}: 0.54 \pm 0.16 ; 45^{\circ}: 0.48 \pm 0.15 ; 90^{\circ}: 0.61 \pm\right.$ $0.20)$. 위등세모근/큰가슴근 비율은 $0^{\circ}$ 와 $45^{\circ}, 45^{\circ}$ 와 $90^{\circ}$ 돌림위치에서 는 유의한 차이가 있었으나 $(\mathrm{p}<0.05) 0^{\circ}$ 와 $90^{\circ}$ 돌림위치에서는 유의한 차이가 보이지 않았다 $(\mathrm{p}>0.05)$.

앞톱니근/위등세모근 비율은 $45^{\circ}$ 돌림위치가 $0^{\circ}$ 와 $90^{\circ}$ 돌림위치보 다 유의하게 높게 나타났다 $\left(0^{\circ}: 4.21 \pm 1.48 ; 45^{\circ}: 4.69 \pm 1.67 ; 90^{\circ}: 4.53 \pm\right.$ 2.15). 앞톱니근/위등세모근 비율은 $0^{\circ}$ 와 $45^{\circ}$ 돌림위치에서는 유의한 차이가 있었으나 $(\mathrm{p}<0.05), 0^{\circ}$ 와 $90^{\circ}, 45^{\circ}$ 와 $90^{\circ}$ 돌림위치에서는 유의한 차이가 보이지 않았다 $(\mathrm{p}>0.05)$.

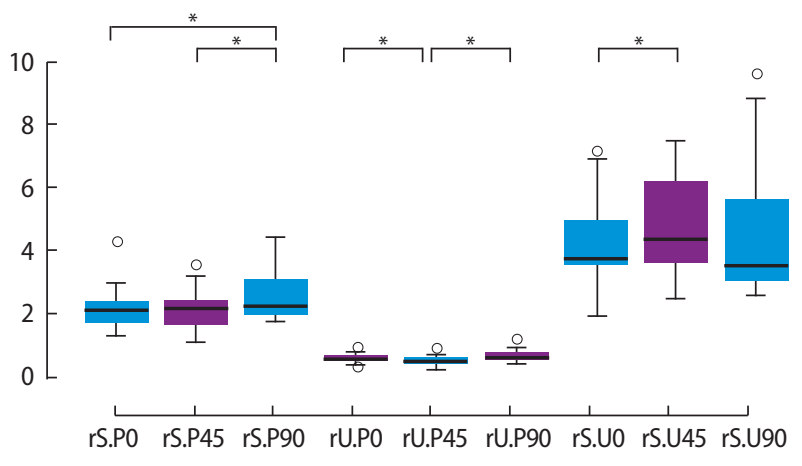

Figure 3. Comparison of three ratios (SA/PM, UTz/PM, SA/UTz) during three $\mathrm{GH}$ joint rotation position. rS.P: serratus anterior/pectoralis major, rU.P: upper trapezius/pectoralis major, rS.U: serratus anterior/upper trapezius, 045 90: GH joint rotation degree, GH: glenohumeral. ${ }^{*} p<0.05$, significant simple effect.

고 찰

어깨가슴관절(scapulothoracic) 주위근육들은 오목위팔관절의 운동 성과 안정성을 유지하고 팔의 정상적인 기능과 움직임에 중요하다. 그 러나 지속적으로 잘못된 자세를 취하거나 반복하게 되면, 어깨복합 체의 근육뼈대(musculoskeletal)의 불균형(imbalance)과 함께 기능부 전(dysfunction)을 초래하게 된다. ${ }^{23,24}$

본 연구는 PUP 운동 시 오목위팔관절의 돌림위치에 따라 어깨가 슴관절 주의근육인 앞톱니근, 큰가슴근, 위등세모근 근활성도를 분 석하고 이들 근육의 연관성을 확인하여 보다 효과적인 선택적 근활 성을 이끌어내기 위해 고안되었다.

PUP 운동은 어깨복합체의 병리를 가지고 있는 경우 재활과 훈련 을 목적으로 수행되었으며 특히, 앞톱니근의 기능강화를 이끌어낸 다. ${ }^{711}$ 큰가슴근과 작은가슴근과 같이 주된 내밈근으로 작용하는 앞 톱니근은 팔을 들어올리는 초기 시기에 등세모근(trapeziuses)들과 함 께 작용하여 어깨뼈의 위쪽돌림근(upward rotator)과 어깨뼈의 안정 근(stabilizer)으로도 작용한다. ${ }^{25}$

본 연구에서는 어깨가슴관절(scapulothoracic) 주위근인 큰가슴근, 앞톱니근, 위등세모근의 근활성과 오목위팔관절의 돌림위치에 따라 의미 있게 차이가 있다는 것을 볼 수 있었다. 큰가슴근 근활성은 $0^{\circ}$, $45^{\circ}, 90^{\circ}$ 의 오목위팔관절 돌림위치에 따라 순차적으로 의미 있게 줄 어들었으며 이와 반대로 앞톱니근은 증가하였다. 반면 위등세모근의 근활성은 오목위팔관절의 돌림위치에 따라 의미 있는 변화는 없었 다. 이 결과는 오목위팔관절의 돌림위치 $0^{\circ}$ 보다 $90^{\circ}$ 일 때 앞톱니근의 근활성은 높고 큰가슴근의 근활성은 낮게 될 것이라는 본 연구의 가 설을 뒷받침하고 있다. 가장 일반적이고 효과적인 앞톱니근의 선택적 강화 훈련으로 PUP 운동이 제안되고 있지만 공통적인 내밈근으로 작용하는 큰가슴근의 상대적으로 높은 근활성은 앞톱니근의 선택 
적 근활성 강화라는 목표를 달성할 수 없게 된다. 앞톱니근보다 활성 화된 큰가슴근은 팔을 들어올리는 동작을 할 때 어깨뼈를 앞쪽으로 당겨지게 하고 결국 아래쪽돌림을 만들게 되어 정상적인 어깨위팔리 듬(scapulohumeral rhythm)을 깨트리는 결과를 가져온다. 그래서 큰 가슴근이 상대적으로 적게 활성화되면서 앞톱니근을 선택적으로 더 욱 활성화시킬 수 있는 오목위팔관절의 $90^{\circ}$ 돌림위치에서의 PUP운 동은 중요한 가치를 가지게 된다. 더군다나 이러한 동작은 조작적인 자세 변화만으로도 이끌어 낼 수 있음에 Park 등히의 능동적 수평 벌 림으로 큰가슴근의 활성을 떨어뜨리고 앞톱니근을 더욱 활성화시킨 운동보다 임상적으로 적용하는 데 있어서 좀 더 편리하게 적용할 수 있게 된다. 여러 PUP 운동 시 보이는 몸통과 가슴 주위 근육들의 근 활성도에 대한 여러 선행 논문 결과와 일치하는 결과라고 할 수 있지 만 ${ }^{16,25} \mathrm{Lee}$ 등 26 의 손의 돌림위치에 따른 어깨가슴근육들의 근활성도 를 분석한 연구에서는 손을 바깥쪽돌림(external rotation) 위치에 놓 은 네발기기 자세에서 PUP 운동 시 큰가슴근의 근활성이 낮게 나타 났다는 결과와 서로 상반된 결과를 보이고 있다.

위팔세갈래근(triceps brichii)과 가슴근(pectorails muscles)들은 PUP 운동 시 초기에 활성이 되고 앞톱니근은 후기에 좀 더 활성이 된 다. 큰가슴근의 복장뼈갈래(sternal head)는 오목위팔관절의 가장 강 력한 폄근(extensor)과 모음근(adductor)으로 작용하며 근섬유의 방 향과 일치하는 오목위팔관절이 굽힘 또는 모음 위치에 있을 때 더욱 더 강력하게 작용한다..$^{27}$ 또한 큰가슴근은 오목위팔관절 $90^{\circ}$ 돌림위 치가 $0^{\circ}, 45^{\circ}$ 보다 근육의 길이가 짧아지게 되고 불충분한 길이로 인해 적절한 힘을 발생하지 못하게 된다. ${ }^{28}$ 근육의 기능은 근육의 가로단면 의 크기와 길이에 따라 달라지게 되고 근육의 길이-장력 관계(The length-tension relationship)는 뼈대근육들의 기본적인 개념이다. 근육 이 생산해내는 힘은 결국 근섬유에 전달된 자극과 함께 근육의 길이 와 속도에 의해서 결정되는 것이다. 그 힘은 중간 정도의 근육길이를 가질 때 가장 큰 힘을 생산하게 되고 이것은 근육원섬유(myofibril)의 굵고 가는 잔섬유(filament)들이 가장 많이 연결되어 있기 때문이 다.29,30 큰가슴근이 오목위팔관절의 돌림위치가 안쪽회전으로 가면 갈수록 그 활성도가 낮아지고 이에 상대적으로 같은 내밈근으로 작 용하는 앞톱니근의 근활성도가 높아진 것이 이러한 근육의 길이에 따른 발생하는 힘의 차이로 사료된다.

앞톱니근/큰가슴근, 앞톱니근/위등세모근은 3 가지의 오목위팔관 절 돌림위치에서 모두 1 보다 높은 비율로 나타났다. 이것으로 PUP 운 동하는 경우 다른 근육들을 억제(inhibition)하면서 앞톱니근을 좀 더 활성화할 수 있다는 것을 시사하고 선행연구들에서도 같은 결과 를 보고하였다.7,917,32 높은 앞톱니근/큰가슴근, 앞톱니근/위등세모근 의 비율은 중요하다. 이것은 앞톱니근, 큰가슴근, 위등세모근의 불균 형을 해소하고 앞톱니근의 선택적 근력강화 운동으로 사용할 수 있
기 때문이다. ${ }^{33}$ 본 연구에서 오목위팔관절의 3 가지 돌림위치 모두 앞 톱니근이 큰가슴근과 위등세모근의 근활성도보다 높게 나왔고 이러 한 패턴이 선택적 앞톱니근 근력강화 운동으로 추천할 만하다.

그러나, 본 연구에서는 앞톱니근/큰가슴근 비율은 오목위팔관절 돌림위치 $90^{\circ}$ 가 $0^{\circ}, 45^{\circ}$ 보다 유의하게 차이가 나타냈다. 큰가슴근의 근 활성도는 오목위팔관절의 $45^{\circ}$ 돌림위치에서의 근활성도가 $0^{\circ}, 90^{\circ}$ 돌 림위치에서의 근활성도보다 높게 나타났고 $45^{\circ}$ 와 $90^{\circ}$ 돌림위치에서 는 유의한차이가 보이지 않았다. 앞톱니근의 근활성도는 오목위팔관 절 $90^{\circ}$ 돌림위치에서 근활성도가 가장 높았다. 큰가슴근 근활성도가 줄어들면서 앞톱니근의 근활성도가 보상적으로 높이진 것이라고 생 각된다. 오목위팔관절 벌림을 수행하는 동안 큰가슴근의 근활성도 가 줄어들고 앞톱니근의 근활성도가 증가되었다는 Park ${ }^{31}$ 등의 논문 의 결과와 일치하는 결과를 나타냈다. 위등세모근의 근활성도, 앞톱 니근/위등세모근, 그리고 위등세모근/큰가슴근 비율 모두가 의미 있 는 차이를 보이지는 않았고 이것은 위등세모근이 MKPUP 수행하는 동안 단지 어깨뼈 위쪽돌림근으로만 사용된다는 것을 보여준다.

따라서 본 연구를 통하여 일반인을 대상으로 오목위팔관절 돌림 위치에 따라 앞톱니근, 큰가슴근, 위등세모근의 근활성도에 의미 있 는 차이가 있다는 것을 확인할 수 있었으며, 이는 어깨복합체 기능손 상을 가진 환자나 어깨가슴관절 주위근육의 선택적 근력강화 등을 위해 임상적으로 널리 이용될 수 있는 기전을 확인한 결과로 의미가 크다. 더 나아가 실제 돌출어깨뼈 환자와 같은 특정 근력 약화를 함 께 가지고 있는 환자를 대상으로 좀 더 긴 시간을 두고 운동의 효과 여부를 비교하는 연구가 필요할 것으로 사료된다.

본 연구는 건강한 성인 남성만을 대상으로 실험을 하였으며 대상 자 수가 적어 다양한 환자에게 특히, 앞톱니근의 근력약화(weakness) 를 가지고 있는 돌출어깨뼈 대상자에게 일반화하기에는 무리가 있 을 것으로 사료되며, 어깨복합체의 기능손상을 가지고 있는 환자를 대상으로 임상적으로 해결할 수 있는 다양한 결과가 이루어져야 할 것으로 사료된다.

\section{REFERENCES}

1. Ludewig PM, Cook TM. Alterations in shoulder kinematics and associated muscle activity in people with symptoms of shoulder impingement. Phys Ther. 2000;80(3):276-91.

2. Cools AM, Dewitte V, Lanszweert F et al. Rehabilitation of scapular muscle balance: which exercises to prescribe? Am J Sports Med. 2007; 35(10):1744-51.

3. Dvir Z, Berme N. The shoulder complex in elevation of the arm: a mechanism approach. J Biomech. 1978;11(5):219-25.

4. Ludewig PM, Cook TM, Nawoczenski DA. Three-dimensional scapular orientation and muscle activity at selected positions of humeral eleva- 
tion. J Orthop Sports Phys Ther. 1996;24(2):57-65.

5. Glousman R, Jobe F, Tibone J et al. Dynamic electromyographic analysis of the throwing shoulder with glenohumeral instability. J Bone Joint Surg Am. 1988;70(2):220-6.

6. Scovazzo ML, Browne A, Pink M et al. The painful shoulder during freestyle swimming. An electromyographic cinematographic analysis of twelve muscles. Am J Sports Med. 1991;19(6):577-82.

7. Decker MJ, Hintermeister RA, Faber KJ et al. Serratus anterior muscle activity during selected rehabilitation exercises. Am J Sports Med. 1999;27(6):784-91.

8. Hintermeister RA, Lange GW, Schultheis JM et al. Electromyographic activity and applied load during shoulder rehabilitation exercises using elastic resistance. Am J Sports Med. 1998;26(2):210-20.

9. Lear LJ, Gross MT. An electromyographical analysis of the scapular stabilizing synergists during a push-up progression. J Orthop Sports Phys Ther. 1998;28(3):146-57.

10. McCann PD, Wootten ME, Kadaba MP et al. A kinematic and electromyographic study of shoulder rehabilitation exercises. Clin Orthop Relat Res. 1993(288):179-88.

11. Moseley JB Jr, Jobe FW, Pink M et al. Emg analysis of the scapular muscles during a shoulder rehabilitation program. Am J Sports Med. 1992;20(2):128-34.

12. Ludewig PM, Hoff MS, Osowski EE et al. Relative balance of serratus anterior and upper trapezius muscle activity during push-up exercises. Am J Sports Med. 2004;32(2):484-93.

13. Martins J, Tucci HT, Andrade R et al. Electromyographic amplitude ratio of serratus anterior and upper trapezius muscles during modified pushups and bench press exercises. J Strength Cond Res. 2008;22(2):477-84.

14. Hiengkaew V, Wichaiwong K, Chaiyakul S et al. Concerning the pectoralis major in active reaching exercise. Electromyogr Clin Neurophysiol. 2003;43(3):157-63.

15. Kim B GW, Lee $S$. The effect of push-up plus exercise with visual biofeedback on the activity of shoulder stabilizer muscles for winged scapula. J Phys Ther Sci. 2010;22(4):355-8.

16. Lee S, Lee D, Park J. The effect of hand position changes on electromyographic activity of shoulder stabilizers during push-up plus exercise on stable and unstable surfaces. J Phys Ther Sci. 2013;25(8):981-4.

17. Schoenfeld B, Sonmez RG, Kolber MJ et al. Effect of hand position on emg activity of the posterior shoulder musculature during a horizontal abduction exercise. J Strength Cond Res. 2013;27(10):2644-9.

18. Basmajian JV DCA, detection, and recording. In: Basmajian JV, DeLuca CJ, editors. Muscles alive: their functions revealedby electromyography.
USA, Williams and Wilkins, 1985: 349-353.

19. Cram JR, Kasmann GS, Holtz. Cram's introduction to surface electromyography. 2nd ed. Jones and Bartlett, 2010: 65-70.

20. Kelly BT, Kadrmas WR, Kirkendall DT et al. Optimal normalization tests for shoulder muscle activation: an electromyographic study. J Orthop Res. 1996;14(4):647-53.

21. Kendall FP ME, Provance PG. Muscles: testing and function. 4th edition. USA, Williams \& Wilkins, 1993: 318-332.

22. Burden A. How should we normalize electromyograms obtained from healthy participants? What we have learned from over 25 years of research. J Electromyogr Kinesiol. 2010;20(6):1023-35.

23. Park SK, Park JM, Lee JH. Effects of a push-up plus exercise program on scapular position and muscle activity in individuals with rounder shoulder posture. J Kor Phys Ther. 2010;22(5):1-8.

24. Mottram SL. Dynamic stability of the scapula. Man Ther. 1997;2(3):12331.

25. Yoon JY KT, Oh JS. Effect of hand positions in electromyographic activity in scapulothoracic muscles during push-up plus. J Phys Ther Korea. 2010;17:8-15

26. Freeman S, Karpowicz A, Gray J et al. Quantifying muscle patterns and spine load during various forms of the push-up. Med Sci Sports Exerc. 2006;38(3):570-7.

27. Donald AN. Kinegiology of the musculoskeletal system. 2nd ed. St. Louis, Mosby Inc., 2009: 167-169.

28. Kisner C CL. Therapeutic exercise: foundation and techniques. 4 edtion. Philadelphia, F.A., Davis Co., 2002: 192-200.

29. Richard LL. Skeletal muscle structure, function and plasticity. 2 edition. Philadelphia, PA, Lippincott Williams \& Wilkins, 2002: 22-45.

30. Szeto GP, Straker L, Raine S. A field comparison of neck and shoulder postures in symptomatic and asymptomatic office workers. Appl Ergon. 2002;33(1):75-84.

31. Park KM, Cynn HS, Yi CH, et al. Effect of isometric horizontal abduction on pectoralis major and serratus anterior EMG activity during three exercises in subjects with scapular winging. J Electromyogr Kinesiol. 2013; 23:462-8.

32. Moon SJ, Kim TH, Roh JS. Acomparison of the serratus anterior muscle activity according to the shoulder flexion angles in a closed kinetic chain exercise and an open kinetic chain exercise. J Kor Phys Ther. 2013; 8(3):369-78.

33. Kim GH, Choe HS, Lee HI et al. The effects of scapular stabilization exercising on dynamic standing balance in stroke patients. J Kor Phys Ther. 2014;26(1):15-20. 